\title{
EL ESTADO Y LA SOCIEDAD EN LA ECONOMÍA POLÍTICA*
}

Fahd Boundi Chrakia

* DOI: https://doi.org/10.18601/01245996.v22n42.08. Recepción: 12-022019, modificación final: 24-09-2019, aceptación: 11-10-2019. Sugerencia de citación: Boundi C., F. (2020). El Estado y la sociedad en la economía política. Revista de Economía Institucional, 22(42), 187-210. Este artículo es parte del proyecto "Desarrollo desigual e integración económica de América del Norte y de Europa". E1 autor agradece a la Dirección General de Asuntos del Personal Académico de la UNAM por la financiación recibida del Programa de Becas Posdoctorales 2018.

a Doctor en Economía. Investigador, División de Estudios de Posgrados, Facultad de Economía, Universidad Nacional Autónoma de México, UNAM, [fboundi@ucm.es], [https://orcid.org/0000-0002-4137-6202] 


\section{E1 Estado y la sociedad en la economía política}

Resumen. Heredera de la filosofía política, la economía inglesa posmercantilista y la fisiocracia francesa, la economía política integró desde su origen la producción, a circulación y la teoría del valor en las teorías del Estado moderno y de la sociedad capitalista. En este trabajo se argumenta que, en la economía política, las concepciones del Estado y de la sociedad están relacionadas con la teoría del excedente. Critica la noción marginalista de la sociedad, hace hincapié en la centralidad de la teoría del excedente, dilucida la antinomia entre Estado y sociedad e identifica los límites del princípio de demanda efectiva de Keynes y Kalecki. La principal conclusión es que las recomendaciones de política económica basadas en metas de inflación, deflación salarial y contención del gasto público buscan aumentar el excedente en las fases de crisis y recesión del ciclo económico.

Palabras clave: economía política, sociedad, Estado, excedente, política económica; JEL: B12, B13, B19, P16

\section{State and society in the political economy}

Abstract. As the heir of political philosophy, the English post-commercialist economy and the French physiocracy, since its origin, political economy has integrated production, circulation and the theory of value into the theories of the modern state and capitalist society. In this paper it is argued that, in political economy, the conceptions of the State and of society are related to the theory of surplus. It criticizes the marginilist notion of society, emphasizes the centrality of the theory of surplus, explained in the conflict between State and society, and identifies the limits of the principle of effective demand of Keynes and Kalecki. The main conclusion is that economic policy recommendations based on inflation, wage deflation and containment of public spending goals seek to increase the surplus in the crisis and recession phases of the economic cycle.

Keywords: Political economy, State, society, surplus, economic policy; JEL: B12, B13, B19, P16

\section{O Estado e a sociedade na economia política}

Resumo. Herdeira da filosofia política, da economia pós-comercialista inglesa e da fisiocracia francesa, a economia política integrou desde sua origem a produção, a circulação e a teoria do valor nas teorias do estado moderno e da sociedade capitalista. Neste artigo, argumenta-se que, na economia política, as concepções de Estado e de sociedade estão relacionadas à teoria do excedente. Critica a noção marginalista de sociedade, enfatiza a centralidade da teoria do excedente, elucida a antinomia entre Estado e sociedade e identifica os limites do princípio da demanda efetiva de Keynes e Kalecki. A principal conclusão é que as recomendações de política econômica baseadas na inflação, deflação salarial e contenção das metas de gastos públicos buscam aumentar o superávit nas fases de crise e recessão do ciclo econômico.

Palavras-chave: economia política, sociedade, estado, superávit, política econômica; JEL: B12, B13, B19, P16 
H $\mathrm{n}$ su Historia de las doctrinas económicas, Eric Roll muestra que los inspiradores del cuerpo teórico de la economía política se remontan a los filósofos políticos, los economistas ingleses posmercantilistas y los fisiócratas franceses. Así, no es extraño que los conceptos de Estado y sociedad ocupen un lugar preeminente en la economía política, como parte constitutiva de la ciencia del gobierno (Sismondi, 2016).

La concatenación del saber perenne que atesoran las obras de Boisguilbert, Petty, Locke y Steuart sembraron entre sus herederos más aventajados la simiente de la que brotaría un sistema del pensamiento económico capaz de unir con notable solidez la teoría del valor, la producción y la circulación con la teoría del Estado y de la sociedad (Smith, 2012; Ricardo, 2004; Sismondi, 2016; Marx, 2006a). La economía política de ese entonces se impuso la ardua tarea de desentrañar en la esfera de la producción la clave de bóveda que da vida a la relación entre el Estado y la sociedad.

Inspirado en esa labor, el objetivo principal de este trabajo es mostrar que las concepciones del Estado y de la sociedad en la economía política están integradas orgánicamente a la teoría del excedente. Con este fin se hace una revisión de la literatura que aborda la crítica de la noción marginalista de la sociedad y los límites de la intervención del Estado asociada al principio de la demanda efectiva.

En la primera sección se muestra la centralidad de la teoría del excedente. En la segunda se analiza la antinomia entre el Estado y la sociedad ocasionada por las relaciones sociales de producción. En la tercera se confronta la teoría del excedente con el principio de la demanda efectiva de Keynes y Kalecki; y en la última se exponen las principales conclusiones.

\section{LA CENTRALIDAD DE LA TEORÍA DEL EXCEDENTE}

Jean-Jacques Rousseau inició su Discurso sobre la economía politica señalando la pertinencia de la distinción entre la economía doméstica y la economía política. Aunque dentro de los límites del gobierno doméstico el derecho de propiedad es ejercido en forma exclusiva por el padre -la en autoridad suprema-, la familia pequeña está destinada a fragmentarse entre varios propietarios que compiten por hacer valer sus intereses particulares.

La conformación de la sociedad civil da lugar al gobierno de la gran familia -el Estado-, que debe garantizar la propiedad privada de cada individuo sujeto a su administración. Mientras que la economía 
doméstica se refiere a la gestión de la fortuna privada, la economía política trata de la administración de la fortuna nacional.

No es incidental, entonces, que la obra cumbre de Adam Smith se titule Una investigación sobre la naturaleza y causas de la riqueza de las naciones, el cual, a juicio de Sismondi (2016), es la definición más precisa de la economía política. Si bien se debe añadir, como hace Blaug (2001), que la economía política se dedicó a desentrañar las leyes de la distribución del ingreso y las leyes que rigen el funcionamiento de la sociedad capitalista.

Esos propósitos concuerdan con las tres reglas superiores enunciadas por Rousseau (2011). El primer mandato de la economía política es el bienestar del pueblo. El gobierno legítimo y popular de la gran familia se ha de guiar por la voluntad general, distinguiéndola de la voluntad particular. La segunda regla es procurar que todas las voluntades particulares converjan hacia la voluntad general por medio de la virtud. Y el tercer deber es la satisfacción de las necesidades de la sociedad haciendo del trabajo el único medio para alcanzar el disfrute de la abundancia.

Sismondi sintetiza estas tres reglas en el objeto de la economía política: la satisfacción material de los individuos a través de la riqueza de la nación, en tanto representación del bienestar social. Advierte, sin embargo, que el objeto de la economía política no reduce el propósito del legislador a alcanzar la igualdad de condiciones, sino el bienestar en todas las condiciones. E1 trabajo, en cuanto fuente única de la propiedad privada y de la riqueza nacional, es el medio para gozar de la abundancia. Por ello, la desigualdad de la propiedad-según Sismondi- es un elemento que impulsa al trabajo, el cual aumenta la riqueza de la nación y el bienestar físico de la sociedad.

No es casual, entonces, que en el prólogo de la tercera edición de los Principios de economía politica y tributación Ricardo sostenga que el principal problema que enfrenta la economía política es inquirir las leyes que rigen la distribución del producto nacional ente sus tres componentes: salarios, ganancias y renta de la tierra. En la desigual distribución de la propiedad de los medios de producción Ricardo encuentra el motor del desarrollo de la sociedad capitalista. Después de exponer la teoría de la renta de la tierra y la teoría de los salarios en los capítulos II y V, el economista clásico inglés recalca en el capítulo VI que el valor de las mercancías se compone de dos partes: la retribución de la fuerza de trabajo y el excedente que se apropia el capital en forma de ganancia. 
Puesto que los salarios están determinados exógenamente por factores socio-históricos, el excedente es la fracción residual del producto que surge merced al valor que crea la fuerza de trabajo por encima de su costo de reproducción. El incremento de los salarios a un nivel que fuese igual al valor del producto eliminaría la ganancia. Pero, según Ricardo, se deterioraría el bienestar físico de la población, pues si el capital no pudiese acumular excedente alguno, tampoco se podría reinvertir para emplear una mayor cantidad de fuerza de trabajo, fuente de la riqueza y el valor. La ganancia es la motivación de la acumulación y la inversión de capital. Y una tasa máxima de ganancia impone un límite a los salarios.

Ricardo observa otro tipo de desigualdad de la propiedad que, en vez de llevar a la prosperidad, condena a un futuro estacionario sin bienestar: la propiedad de la tierra. En virtud de los rendimientos decrecientes, la expansión de la producción agrícola en tierras cada vez menos fértiles tiende a ampliar la renta de la tierra, que se destina a cubrir los gastos improductivos de los terratenientes. De modo que la ganancia experimenta una tendencia descendente que irá mermando la acumulación del capital hasta alcanzar el estado estacionario. Aunque esta preocupación de Ricardo es propia de las condiciones de su época y hoy puede parecer un anacronismo, su análisis corresponde al objeto general de la economía política.

Sobre esta cuestión cabe decir que la economía política infiere el particular a través del universal concreto, para usar términos hegelianos. Marx subrayó que el método de la economía política comienza por lo concreto y devela en su transcurso ciertas relaciones generales abstractas. Y señaló que, a partir de abstracciones de la mayor simpleza -trabajo, división del trabajo, valor de cambio-, la economía política llegó a los conceptos de Estado, intercambio entre naciones y mercado mundial. El método de la economía política es un proceso de síntesis, primero hace un viaje de ida - de lo concreto a lo abstracto- - después emprende el viaje de retorno - de lo abstracto a lo concreto- (Marx, 2014a).

E1 concepto filosófico de devenir impregna a la economía política desde su origen. En la medida en que todo fluye, los clásicos (Smith, 2012; Ricardo, 2004; Sismondi, 2016) y Marx (2006c) concibieron el capital como movimiento perpetuo. La competencia es el reflejo de dicho movimiento. Dentro de una rama de la producción, la lucha para producir más barato induce, en forma endógena, el cambio técnico que deviene en un aumento de la escala de la producción (Shaikh, 2016; Jiménez, 2018). 
En la competencia entre ramas de la producción, el capital migra a los sectores de mayor rentabilidad y uniforma las tasas de ganancia a través de los excesos de oferta y demanda que, tendencialmente, hacen converger los precios de mercado a los precios naturales en el largo plazo.

La competencia es el medio a través del cual se ejercen las leyes económicas que gobiernan el orden capitalista, donde el capital es un valor en continuo proceso de auto valorización (Marx, 2006a, 2014b). En la economía política, el movimiento del capital es la causa de la riqueza de las naciones, aunque se manifieste en un desarrollo desigual de las clases sociales, los sectores productivos, las regiones y las naciones. No por casualidad Schumpeter (2008) concibió el modo de producción capitalista como un proceso evolutivo en desequilibrio permanente.

La concepción schumpeteriana está enraizada en la economía política, pues considera que las transformaciones de la sociedad capitalista son provocadas endógenamente, por el movimiento del capital que destruye lo viejo y crea lo nuevo. Por ello, Schumpeter rechazó la teoría de la competencia perfecta de Marshall y Wicksell, que paradójicamente excluía el movimiento del capital.

La visión marginalista implica un capitalismo estacionario que, en sentido estricto, es incompatible con el cuerpo teórico de la economía política. El equilibrio marginalista es ajeno a las leyes de movimiento de la sociedad capitalista. Como el objeto de la economía marginalista es la asignación eficiente - en el sentido de Pareto- de recursos escasos, su método deduce el universal concreto del particular. Y puesto que el capitalismo es un sistema en proceso, el intento de analizar su funcionamiento a partir de sus elementos no puede, en modo alguno, extraer conclusiones generales que aporten la comprensión cabal de las leyes del movimiento de la sociedad moderna.

El abismo que separa la economía marginalista de la economía política se ensancha aún más al considerar la relación entre esencia y apariencia. Desde el siglo XVII, la economía política abandonó el análisis de lo aparente para llegar a la esencia del objeto de estudio (Blaug, 2001). James Steuart, por ejemplo, atacó con vehemencia el dogma de Hume, según el cual el nivel de precios de las mercancías crece en proporción directa a la oferta monetaria (Marx, 2002; Shaikh, 2016; Boundi, 2018). En su afán por descubrir la esencia que se esconde detrás de la aparente correspondencia de la oferta monetaria con la inflación, Steuart concluyó que la suma de los precios era la que determinaba la cantidad de dinero en circulación, y no al contrario. 
Cuando el oro y la plata son moneda, su exceso se retira de la esfera de circulación en virtud de su función como reserva de valor. El atesoramiento del excedente de monedas de oro y plata eleva las reservas bancarias, reduce la tasa de interés y estimula el crédito (Marx, 2002; Shaikh, 2016; Boundi, 2018).

Pese a su agudeza, James Steuart también fue presa de las apariencias al considerar que la venta de las mercancías a un precio superior a su valor era la fuente de la ganancia (Marx, 1980a). Quesnay (1972), Smith y Ricardo hicieron fuertes objeciones a esta idea de Steuart. En la economía política, la teoría del excedente explora lo que se oculta detrás de las apariencias para revelar la esencia: el origen de las ganancias en la esfera de la producción.

En el capitalismo, el excedente es el residuo que se obtiene al remunerar el trabajo asalariado por debajo de su productividad. E1 excedente se realiza en la esfera de circulación, como ganancias del capital. La teoría del excedente, de la economía política, culminó en Marx (2006a), con su teoría del plusvalor.

La economía política clásica, a pesar de haber sido cuidadosa al aislar el ser del parecer, fue cautiva de la falsa conciencia que reduce las relaciones sociales de producción a meras relaciones entre objetos. El carácter fetichista de la mercancía, el dinero y el capital se destaca en la crítica de Marx (2006a) a la economía política clásica.

Marx rompió con la idea del capital como trabajo acumulado - u objetivado- de Smith y Ricardo al resaltar su carácter social e histórico. En cuanto relación social, el capital no se puede definir solamente como la suma de las cantidades físicas de maquinaria, equipos y materias primas, pues está compuesto por mercancías, valores de cambio y magnitudes sociales (Marx, 1968). Un objeto [valor de uso] que puede servir como medio de producción solo será capital si contribuye a la creación de valores de cambio. De lo contrario, cualquier objeto habría sido capital en el pasado, tornándolo en una categoría ahistórica (Marx, 2014a).

Sismondi (2016) percibió antes que Marx la doble faz de la producción capitalista (Guerrero, 2010). Pues advirtió que mientras que la riqueza de la nación corresponde a la cantidad de valores de uso que produce el trabajo concreto, el valor [de cambio] -una idea abstracta y social expresada en el capital- es engendrado por el trabajo social abstracto.

La contradicción entre la riqueza y el valor devela el principio que rige el movimiento del capitalismo: el valor de cambio. El desequilibrio se convierte en norma, porque la producción no tiene como propósito servir las necesidades de consumo [valor de uso], sino valorizar el 
capital [valor de cambio]. En la distinción entre el valor de uso y el valor de cambio de la fuerza de trabajo reside el fundamento del orden económico moderno: el excedente. Esta dualidad marca la relación de la sociedad civil con el Estado, tema que es el objeto de análisis de la siguiente sección.

\section{ANTINOMIA ENTRE ESTADO Y SOCIEDAD}

En su célebre Discurso sobre el origen de la desigualdad de los hombres, Rousseau describe el camino que recorrió la humanidad desde su estado natural hasta la conformación de la sociedad civil. Para responder a la pregunta: ¿cuál es el origen de la desigualdad política entre los individuos?

La respuesta no se puede encontrar en la naturaleza. En el estado natural, cuando no existían las artes ni la propiedad, el individuo nacía y moría libre, porque su existencia no estaba ligada a la de los demás (Rousseau, 2014a). En la sociedad civil, sin embargo, el individuo que nace libre queda encadenado por todas partes (Rousseau, 2014b). El primero que, después de vallar una porción de la tierra, exclamó ¡esto es mío! y persuadió al resto que así había de ser, puede y debe reclamarse como el fundador de la sociedad civil (Rousseau, 2014a). Para que este fundador pudiera apropiarse de la tierra, tuvo que existir primero el trabajo. El que cultiva la tierra, escribe Rousseau, es por derecho el propietario del producto que ha labrado. Pero, por otra parte, el reparto desigual de los talentos llevó a que ciertos trabajos privados fuesen más productivos que otros.

El derecho de propiedad se tornó, rápidamente, en el derecho a apropiarse el producto del trabajo ajeno. La concentración de la propiedad forjó unas relaciones sociales específicas que fueron la primera manifestación de la desigualdad política. Tal es el origen de la riqueza, pues no se es pobre o rico en general, sino en relación con los demás (Rodríguez, 2015).

De allí proviene la crítica de la economía política contra la ilusión de la economía marginalista, que cree poder conocer cabalmente los conceptos de la sociedad y la riqueza por medio del náufrago de Defoe. Crusoe no puede decir mucho de la riqueza, pues su soledad en la isla no lo hace rico ni pobre a ojos de nadie. En ausencia de sociedad, la riqueza no es perceptible.

La sociedad es un complejo sistema orgánico de interrelaciones, que alberga una estructura de clases definida por las relaciones sociales de producción específicas que imperan en cada momento de la historia. 
La génesis de la sociedad moderna es relatada en lo que Smith (2012) y Marx (2006a) 1lamaron, respectivamente, acumulación primitiva y acumulación originaria. Dicha acumulación fue el punto de partida del orden social capitalista. Se trata del proceso histórico que convirtió las mercancías y el dinero en capital, pues produjo el divorcio formal entre el productor y sus medios de producción. Se expropió la tierra, se concentró la propiedad de los medios de producción y la producción se organizó con base en el trabajo asalariado (Marx, 2006a).

Las incipientes relaciones sociales de producción de la sociedad moderna pronto enfrentaron a dos tipos de propietarios: los poseedores de fuerza de trabajo y los tenedores de capital. Entre ambos, se irguió una constelación de terceras personas cuya existencia dependía de cuán grande fuese el excedente que brotara del trabajo productivo. La economía política comprendió desde su inicio que la sociedad civil descansa en dos pilares fundamentales: la satisfacción del interés privado y la dependencia del individuo de otros individuos.

La multitud de intereses contrapuestos requiere un pacto social que formalice el estado social. Entonces surge el problema de encontrar una forma de asociación que se encargue de defender y proteger a los individuos y la propiedad de cada asociado. En virtud de esa asociación, cada cual solo habrá de obedecerse a sí mismo encontrándose libre como antes. La solución a dicha disyuntiva es el contrato social (Rousseau, 2014b).

Para que el contrato social sea efectivo, debe existir una realidad superior cuyo principio sea la libertad y la igualdad del individuo: el Estado moderno. Al que Hegel (1993) define como una necesidad exterior, un poder supremo al cual se deben subordinar las leyes y los intereses privados. Se trata de la marcha de Dios en el mundo. $\mathrm{Su}$ fundamento es la fuerza que proviene de la razón realizada como voluntad. Rousseau (2014b) diría además que las fuerzas del Estado están comandadas por la voluntad general. Por tanto, su fin último es procurar el interés común. El pacto social da vida y existencia al Estado. Su voluntad y su acción están determinadas por la legislación.

No obstante, von Stein (1981) advierte que el principio de libertad e igualdad de los individuos corresponde al Estado puro, cuya existencia es una mera abstracción. Hegel, en cambio, considera que la idea del Estado posee una realidad inmediata expresada en la constitución [voluntad] y el derecho político interno [actividad]. Von Stein objeta a su maestro que la personalidad del Estado es el reflejo de las personalidades de quienes lo componen. En cuanto concepto, el Estado 
no tiene una realidad inmediata sino una existencia abstracta. Son los individuos que integran el Estado quienes le dan su realidad. En la medida en que proceden de la sociedad civil, han de representar sus intereses. Los dos momentos de la realización del Estado -su voluntad [la constitución] y su actividad [la administración]- son captados por el principio de la sociedad civil. El Estado real es aquel que existe como producto de su relación dialéctica con la sociedad civil (von Stein, 1981).

En la sociedad moderna, la dependencia entre individuos es tejida por las relaciones de producción que subsumen el trabajo en el capital. Puesto que el orden social es definido por el tipo de propiedad reinante, la estructura de clases se configura conforme a tales relaciones de producción. La sociedad moderna encierra el sempiterno conflicto entre trabajadores asalariados y propietarios del capital.

La economía política advierte la antinomia entre el Estado y la sociedad civil, la cual proviene de la sujeción, que comienza cuando la clase dominante se adueña de la voluntad y de la actividad del Estado (von Stein, 1981). El principio sagrado de la Constitución es la propiedad privada, el derecho a poseer el capital. La administración está formada por un cuerpo burocrático cuyos intereses están en sintonía con los de la clase dominante. El Estado real queda así a merced de la sociedad civil.

El proceso de sujeción prosigue cuando la clase dominante asegura el monopolio de la propiedad privada del capital. La clase subordinada permanece desposeída a través de diversos mecanismos que le impiden apropiarse el excedente que genera su trabajo. Esa es la ley general del movimiento de la sociedad, la cual revela que el Estado real contraviene la idea de que es la esfera de la razón y lo universal (Marx, 1974; von Stein, 1981).

Por ello, un ferviente crítico de la interpretación económica de la historia, como Weber (1998), dice que el Estado moderno es una relación de dominación de individuos por individuos, que subsiste merced a la violencia legítima. Así, el monopolio de la violencia es un medio que usa el Estado real para legitimar el orden social.

E1 gran mérito de los economistas políticos es su capacidad para integrar la teoría del Estado en su teoría de la producción, la distribución, la circulación y la realización del excedente. Esto no debería sorprender pues, como muestra Roll (2017), la filosofía política que arrancó en el siglo XVI con Bodin y Maquiavelo es una de las tres corrientes de pensamiento que dieron origen a la economía política. 
Llegados a este punto, cabe preguntar cómo trata de resolver la economía política la antinomia entre el Estado y la sociedad civil. Primero se debe decir que las respuestas son diversas y no coincidentes. La atención se centrará en algunas voces autorizadas. En primer lugar, la de Rousseau, que merece este privilegio por la influencia de su pensamiento en la construcción del Estado nación.

En el Contrato social, Rousseau identifica el soberano con el pueblo; la soberanía es inalienable e indivisible. El príncipe [poder ejecutivo] y el soberano [poder legislativo] nunca podrán ser la misma persona, pues de no ser así habría un gobierno sin gobierno. Quien hace las leyes no debe ejecutarlas y los intereses particulares no se deben confundir con los asuntos políticos.

Puesto que la soberanía es la voluntad general, no puede ser representada ni enajenada. Al ser una e indivisible, solo puede ser ella misma o ninguna. Los diputados de la asamblea nacional no representan al pueblo, son sus comisarios. Se llega así a la solución de Rousseau, cuyo contenido presenta en la continuación del capítulo XIII del segundo libro del Contrato social: el pueblo ha de reunirse periódicamente en asambleas jurídicas, cuya legitimidad depende de que sean convocadas por los magistrados elegidos para tal efecto. En estas asambleas legítimas la autoridad del soberano se perpetúa al hacer de las leyes actos verdaderos de la voluntad general. Solo así-sostiene Rousseau-, concordarán los principios del Estado y la sociedad civil.

Esta solución no convenció a Hegel, quien la criticó en los parágrafos 308 y 309 de los Principios de la fllosofía del derecho. Debido a su multitud, su función y su ocupación, el aspecto móvil de la sociedad civil solo puede ser intercedido por los diputados. En cuanto delegados de la sociedad civil, los diputados son la representación efectiva de la sociedad civil, a diferencia de las asambleas jurídicas de Rousseau, formadas por individuos que se reúnen, en forma disuelta y atomística, para realizar actos singulares y transitorios.

En el parágrafo 308, Hegel argumenta que la idea de Rousseau de que todos deben ser parte activa en la deliberación y la decisión de los asuntos generales impone un elemento democrático desprovisto de toda forma racional al organismo del Estado, porque no rebasa la determinación abstracta de ser miembro del Estado. Hegel subraya que esta idea de que todos deben participar en los asuntos del Estado supone implícitamente que todos poseen pleno conocimiento de dichos asuntos, lo cual es irracional. Hasta aquí Hegel solo ha defendido la democracia representativa frente a la democracia participativa de Rousseau. 
Hegel resuelve la antinomia ente el Estado y la sociedad en parágrafos anteriores a su crítica de Rousseau. En el parágrafo 279 argumenta que la personalidad del Estado solamente es real en la figura del monarca. Para Hegel, el concepto de soberanía del pueblo de Rousseau es confuso pues solo busca oponerse a la soberanía del monarca. En un pueblo que se concibe a sí mismo como totalidad orgánica, la soberanía reside en la personalidad del todo que, llevada a la realidad mundana, es la persona del monarca. Por ello, para Hegel la monarquía constitucional y el monarca ponen fin a la contradicción entre el Estado y la sociedad. En el príncipe se congregan los diferentes poderes en una unidad individual, que como principio y fin del todo da lugar a la forma política suprema: la monarquía constitucional. La voluntad del príncipe [filósofo], una e indivisible, es la voluntad general. Así, los intereses privados se reconcilian con el interés común.

Marx (1974) fue muy crítico a este respecto, porque la idea hegeliana de que la personalidad del Estado toma realidad a través del monarca equivale a decir que el género humano es un solo individuo. Para Marx, la disolución de las relaciones sociales de producción capitalistas es la manera de eliminar la contradicción entre Estado y sociedad civil.

Von Stein es más conservador que Marx pues, igual que Hegel, concibe la monarquía constitucional como el puente hacia la reconciliación. Una vez que la forma real del Estado es modelada por la sociedad civil, se inicia el movimiento hacia la libertad. La clase subordinada emprende un movimiento social contra el orden que la excluye de la propiedad del capital.

En opinión de von Stein, la revolución social que anhela la clase subordinada abriga innumerables contradicciones que conducen a la tiranía. Esto lo lleva a concluir que la oposición entre el Estado y la sociedad no pasa por la revolución social, sino por la reforma social. Para que la clase subordinada no ambicione la toma del poder político, el Estado ha de suprimir los obstáculos que impiden su participación en la posesión del capital. La armonía social encuentra en la monarquía constitucional la forma política ideal para su realización, en cuanto es la concepción misma del Estado.

A juicio de Marcuse (1994), von Stein neutraliza los elementos críticos de la dialéctica de Hegel al reducirla a un acervo de leyes objetivas que claman por la reforma como procedimiento idóneo para superar las contradicciones del orden capitalista. Aunque reconoce que von Stein percibió que las antinomias intrínsecas a la sociedad moderna son el motor que alienta su movimiento. 
La tesis reformista de von Stein se confundiría casi un siglo después con la Teoría general de la ocupación, el interés y el dinero de Keynes. En comunión con von Stein, los economistas en los que influyó la obra de Keynes creyeron factible la reconciliación social por la vía de la intervención del Estado. Esta idea obliga a enfrentar la teoría del excedente de la economía política con el principio de la demanda efectiva de Keynes y Kalecki, para ver sus límites.

\section{LA ECONOMÍA POLÍTICA DESPUÉS DE KEYNES}

En el primer capítulo de la Teoría general, Keynes indica a sus lectores la importancia del término "general" en el título de su obra, cuyo propósito es confrontar su cuerpo teórico con el de la economía clásica. Keynes denominaba clásica no solo a la economía política propiamente tal, sino también a la escuela marginalista encabezada por Marshall, Edgeworth y Pigou, a quienes consideraba continuadores legítimos de Ricardo.

Al equiparar la economía política a la economía marginalista, Keynes le atribuyó tres principios teóricos: 1) el salario es igual a la desutilidad de la ocupación efectiva, 2) no hay desempleo involuntario y 3) la oferta crea su propia demanda. En su opinión, el tercero es central en la doctrina de la economía política que cultivaron Marshall, Edgeworth y Pigou hasta convertirla en el soporte fundamental de la teoría clásica moderna [marginalista]. Según Keynes, el triunfo de la ley de Say se debió a la poco clara exposición de Malthus sobre la insuficiencia de la demanda efectiva que se deriva del exceso de ahorro. Por ello, Ricardo reconquistó fácilmente a Inglaterra y su figura quedó asociada al triunvirato marginalista de Cambridge (Keynes, 2014).

Pero Keynes no ahondó en las causas que llevaron a la derrota teórica de Malthus frente a Ricardo. En las Teorías sobre la plusvalía, Marx (1980b) dedica el capítulo XIX a Malthus y su obra. En ese capítulo, Marx reconoce el mérito de Malthus por haber revelado que las mercancías no se intercambian en la esfera de la circulación conforme a la ley del valor de Ricardo; aunque Malthus confundió la valorización del dinero con el valor de la mercancía.

Malthus retomó la concepción de James Steuart según la cual la ganancia brota de la circulación, donde las mercancías se venden a un precio superior a su valor. En Keynes sobrevive esta idea del origen de la ganancia, pues sostiene que el monto de los beneficios depende de la demanda efectiva. 
En cambio, Ricardo y Marx mostraron que la tasa de ganancia realizada es el determinante de la inversión, con la que establece una relación de causalidad unidireccional. El otro gran defensor del principio de la demanda efectiva-Kalecki-discrepa de Ricardo y de Marx, quien en su Teoría de la dinámica capitalista argumenta que el gasto de los capitalistas (la inversión más el consumo privado) determina sus ganancias, y no al contrario.

Cárdenas del Rey (2018) señala que en la teoría kaleckiana de la inversión hay una relación de causalidad circular. Por una parte, la inversión presente eleva el volumen de las ganancias a través de la expansión de la demanda agregada. Por la otra, el aumento de las ganancias esperadas influye positivamente en las decisiones de inversión. Cabe preguntar de dónde procede lo que gastan los capitalistas, pues Kalecki no se preocupó -como Malthus y Keynes- de esbozar siquiera una teoría del valor.

La prisa de Malthus para identificar el origen de la ganancia lo llevó a confundir el precio de costo con el valor de la mercancía propiamente dicho. Al no realizarse excedente alguno en la esfera de circulación, Malthus consideró que las empresas obtenían sus ganancias fijando un margen sobre los costos de producción. En la visión malthusiana, el monto de los beneficios depende del nivel de demanda efectiva, sin explicar cuál es la fuente del poder de compra que permite intercambiar las mercancías.

Keynes y Kalecki incurren en esa misma deficiencia, pues subordinan la producción a la demanda agregada sin aclarar la procedencia del poder adquisitivo que propicia el consumo y la inversión. La economía política esclarece este enigma mediante la teoría del excedente. A partir del Tableau économique, Quesnay entendió que, en virtud del flujo circular, los ingresos que cubren los gastos provienen de la producción. Al valor creado en la producción le corresponde un poder de compra equivalente. El hecho de considerar el flujo circular fue suficiente para que Ricardo triunfara en la batalla teórica contra Malthus, aunque conviene señalar que la doctrina de Mill y Say no conquistó la economía política, como asevera Keynes.

La importancia que atribuyen Steuart, Tooke (1857) y Marx (2002 y 2006a) al atesoramiento de dinero revela la distinción entre el deseo de compra y el poder de compra. En palabras de Marx (2006a), nadie puede vender sin que otro compre, pero nadie tiene la necesidad de comprar tras haber vendido. El atesoramiento interrumpe la circulación de mercancías debido al deseo de los propietarios de capital de mantener sus ganancias en forma de dinero (Marx, 2006a; de 
Brunhoff, 1967). Surge entonces un desajuste entre la producción y la demanda efectiva que anula la ley de los mercados de Mill y Say, y las crisis se convierten en una posibilidad. La acumulación de capital (reinversión del excedente) es la autoridad suprema que dirige la demanda agregada. A diferencia de lo que sostiene Keynes en la Teoría general, la economía política integra una teoría monetaria de la producción que rechaza de plano la falsa dicotomía entre el sector monetario y el sector real propia del marginalismo.

Como consecuencia necesaria de lo anterior, de las teorías del excedente y el dinero de la economía política se desprende la crítica del multiplicador de Kahn, Keynes y Kalecki. Por ello, en opinión de Carchedi (1991), la tesis de que el aumento del gasto autónomo de los agentes privados induce un incremento de los ingresos es una falacia. Carchedi señala que los gastos autónomos han de financiarse con el dinero que, por diversas razones, se atesoró en el pasado. El atesoramiento o, usando la terminología de Marx, la petrificación del dinero significa que antes se produjeron mercancías que no entraron en circulación. Dichas mercancías luego se podrán vender a cambio del dinero atesorado que servirá para cubrir los gastos.

En este caso se realiza un valor producido previamente, pero no hay creación de nuevo valor ni el incremento del ingreso nacional que presupone el multiplicador keynesiano. Como alternativa, Carchedi (2012) propone el multiplicador marxiano, según el cual la producción nacional será mayor cuanto mayor sea la tasa general de ganancia. La crítica de Carchedi se basa en uno de los pilares de la teoría del excedente de la economía política: la distinción entre trabajo productivo y trabajo improductivo. Como ya se señaló en la primera sección, la economía política se ocupó de la naturaleza y la causa de la riqueza de las naciones, considerando el trabajo como su única fuente. Los economistas políticos no se detuvieron en la apariencia del objeto de conocimiento, sino que penetraron en sus diversas capas para hallar su esencia: el trabajo productivo.

Smith, el primer economista político que se dedicó a la tarea de distinguir el trabajo productivo del trabajo improductivo, definió el trabajo productivo como aquel que sirve para aumentar la acumulación del capital, mientras que el trabajo improductivo es un freno para la riqueza. Marx amplió esta definición distinguiendo el trabajo productivo en general del trabajo productivo para el capital. La concepción de Marx es superior a la de Smith, en cuanto el trabajo productivo -creador de plusvalor para el capital-engloba las mercancías tangibles y los servicios (Guerrero, 1994). 
Por falta de una teoría del excedente, esta discusión es soslayada por Keynes, Kalecki y los teóricos del crecimiento impulsado por la demanda (Minsky, 1986; Bhaduri y Marglin, 1990; Davidson, 2011; Lavoie, 2016). Aunque Keynes y Kalecki insistieron en la centralidad de la inversión, ambos atribuyeron un papel esencial a la intervención del Estado en el combate al desempleo.

Usando un lenguaje marginalista, en el capítulo X de la Teoría general Keynes deduce que el desempleo involuntario convierte todo gasto del gobierno financiado con deuda en creador de riqueza nacional. En "Aspectos políticos del pleno empleo"(1943), Kalecki plantea con más detalles que la inversión pública y los subsidios al consumo sufragados con deuda del Estado son un estímulo necesario para que la demanda efectiva crezca hasta el nivel del pleno empleo. El gasto del gobierno eleva directa e indirectamente el empleo de modo que genera nuevos ingresos que amplían la demanda secundaria de bienes salario y de medios de producción. Pero Kalecki se pregunta de dónde proviene el dinero que los particulares proporcionan al Estado, si no reducen su inversión y su consumo presentes. Su respuesta es que la economía presta al Estado mercancías cuya producción se financió con títulos de deuda pública. Pero esta respuesta elude la distinción entre inversión productiva e inversión improductiva.

La economía política tuvo un especial cuidado en delimitar la frontera que separa el gasto productivo del gasto improductivo. E1 dinero que adelantan las empresas para pagar los salarios de los trabajadores productivos y adquirir medios de producción es un gasto de inversión productiva porque aumenta el excedente. En cambio, los subsidios al consumo, el mantenimiento del aparato burocrático y otros gastos corrientes del Estado son gastos improductivos que no elevan el ingreso nacional, porque solo reasignan los recursos de los que dispone la economía para realizar el valor ya producido. Al parecer, Kalecki olvidó algo que la economía política ya entendía desde tiempos de Rousseau (2014b): el Estado no puede subsistir sin el excedente generado por el trabajo productivo.

Como bien se sabe, Ricardo integró la teoría de la tributación en la teoría del excedente, considerando uno de los límites de la propuesta de Kalecki y otros autores (Minsky, 1986; Bhaduri y Marglin, 1990; Lavoie, 2014). En el capítulo VIII de los Principios de economía politica y tributación, Ricardo mostró que los impuestos recaían en última instancia sobre el excedente. Para Ricardo, un aumento del consumo improductivo del Estado cuando la producción está estancada merma 
el fondo destinado a la inversión productiva y debilita la acumulación del capital, el motor del crecimiento económico.

Puesto que el modo de producción determina la manera de distribuir el ingreso entre las clases que conforman la sociedad, durante las crisis y las recesiones propias del capitalismo todo intento de estimular la demanda efectiva mediante el gasto financiado con impuestos deteriorará la tasa general de ganancia, el acicate de la inversión productiva. Esto no significa que en todas las situaciones sea perjudicial para el capital soportar la carga tributaria que cubre los gastos públicos.

Ricardo diferenció los sectores básicos que producían bienes salario y medios de producción de los sectores no básicos dedicados a producir bienes suntuarios. De acuerdo con Ricardo, las condiciones técnicas de producción de los sectores no básicos nada influyen en la determinación de la tasa general de ganancia y los precios de las mercancías básicas. Por ello, un impuesto a los bienes de lujo no tiene el menor efecto sobre la tasa de ganancia de los sectores básicos ni merma el crecimiento económico. Ricardo recomienda entonces que los gastos improductivos del Estado se cubran con el recaudo de impuestos a las mercancías no básicas.

En la Crítica de la teoría del capitalismo monopolista de Estado (1980), Théret y Wieviorka proponen discutir un planteamiento basado en la teoría del excedente: el abaratamiento de los costos de reproducción de la fuerza de trabajo como consecuencia del gasto social del Estado. Estos autores señalan que los impuestos - en cuanto deducciones de las ganancias establecidas por el Estado- tienen tres destinos: los gastos corrientes para sostener el aparato del Estado y asegurar su monopolio de la violencia; los medios de vida colectivos -educación, salud, vivienda, entre otros- a disposición de los asalariados, y los medios de producción colectivos que constituyen la infraestructura económica y contribuyen a la expansión del capital productivo. Théret y Wieviorka argumentan, con acierto, que los medios de vida colectivos son un adelanto socializado de la parte que el capital dedica a los salarios. Por ello, el gasto público puede abaratar el costo de reproducción de la fuerza de trabajo hasta el nivel que consiente la ampliación del excedente apropiado por el capital.

Podría parecer que la teoría de la hacienda pública de la economía política avala la solución de von Stein. Según este autor, el Estado social surge en la historia para apaciguar el conflicto social, proporcionando medios de vida colectivos y creando leyes que protegen a la clase subordinada frente a la clase dominante. Aunque los impuestos 
son deducciones del excedente, la intervención del Estado puede garantizar, en ciertas situaciones, la rentabilidad del capital. Cabe entonces preguntar: ¿el principio de demanda efectiva de Keynes y Kalecki resuelve la antinomia entre el Estado y la sociedad civil?

La respuesta solo puede ser negativa. La financiación de los gastos improductivos del Estado posee un límite: la tasa máxima de ganancia (Carchedi, 1991 y 2012). Si el Estado retira dinero de la circulación a través de impuestos y después lo destina a comprar mercancías, solo realiza el valor creado previamente. Así se vuelve a la primera conclusión: toda acción para estimular la demanda efectiva en un escenario sin crecimiento de la producción merma la acumulación de capital. No obstante, debe reconocerse que Keynes y Kalecki concibieron la emisión de deuda del Estado como fuente ideal para cubrir los gastos públicos.

Uno de los más aventajados discípulos de Kalecki-Hyman Minsky- propone que el banco central actúe como prestamista de última instancia para atenuar la inestabilidad financiera (1986). Según su enfoque, el banco central debe comprar los títulos de deuda del Estado $y$, contrapartida, incrementar la base monetaria. Con base en la idea de Kalecki de que las ganancias dependen de la demanda efectiva, Minsky argumentó que el gasto del Estado, por una equivalencia contable, era un ingreso para las empresas. Si todo lo demás se mantiene constante, cuanto mayor es el déficit del Estado más elevado es el monto de ganancias.

La propuesta de Minsky descansa en la hipótesis de Knapp (1924) y Keynes (1971), según la cual el dinero es una criatura de la ley. Así, el valor del dinero no está determinado por el trabajo social abstracto y no depende de la relación con las divisas y los metales preciosos (tipo de cambio nominal). Minsky sostiene que el valor del dinero está dado por los impuestos a la producción; así se conecta con la hacienda funcional de Lerner (1951). Por influencia de Knapp y Keynes, Lerner señaló que las políticas fiscales no se podían deslindar de las políticas monetarias. En su crítica de las finanzas sanas, Lerner argumentó que mientras el Estado tuviera el respaldo de la emisión monetaria del banco central, no había motivos para preocupase por los déficits fiscales elevados. Y concluyó que el Estado nunca podía entrar en quiebra.

Tales son algunos de los elementos en los que se apoyó Minsky para justificar que el banco central y el Estado actuaran como prestamista y empleador de última instancia para alcanzar el pleno empleo. Pero, como muestra King (2005), Minsky no se preocupó en absoluto 
por la producción, e incurrió así en la omisión de Keynes y Kalecki: obviar la fuente creadora del ingreso. La emisión de dinero acarrea la apropiación del poder adquisitivo surgido en la esfera de la producción; el gasto del Estado solo realiza el valor creado anteriormente (Carchedi, 1991, 2012).

Marcuse muestra que, antes de Hegel, la economía política entendía que las unidades que integran los diferentes modos de asociación se presentaron en la historia conforme a la siguiente cronología: la familia, las instituciones sociales del trabajo, la propiedad, las leyes y, finalmente, el Estado. Esta secuencia contradice el aserto de Knapp, pues el dinero aflora en el proceso social del intercambio. Puesto que el principio que rige la sociedad implica la dependencia mutua entre individuos, este nexo social se manifiesta en el valor de cambio. El valor de cambio se encarna en una mercancía particular que representa a todas las demás en la esfera de la circulación (Marx, 2014a).

E1 producto del trabajo privado convertido en mercancía alberga la contradicción de ser una unidad de valor de uso y de valor de cambio que da lugar al nacimiento del dinero. La propiedad privada, cuya fuente es el trabajo, se manifiesta no solo en los valores de uso sino también en el dinero. La propiedad privada antecede e inspira las leyes que la convierten en derecho legal. Y el respeto de las leyes que legitiman la propiedad privada requiere la existencia de un poder supremo, el Estado.

Según Hegel, el derecho constitucional es, por definición, el derecho privado que hace del derecho político el modo de legalizar la propiedad, por cuanto la oposición entre el Estado y la sociedad opone el Estado real a su forma ideal. Por ello, decir que el dinero es una criatura del Estado equivale a decir que la sociedad moderna es una criatura del Estado.

E1 mismo Kalecki (1943) reconoció que las políticas para lograr el pleno empleo, más pronto que tarde provocarían la reacción del capital. Un régimen de pleno empleo permanente da a la clase subordinada un alto poder de negociación que amenaza el orden capitalista. En las fases de auge, la clase dominante se opondrá ardientemente a las políticas de pleno empleo para asegurar su hegemonía social. En las crisis y las recesiones, estará dispuesta a hacer concesiones a la clase subordinada en aras de la paz social. Ese es el ciclo político de Kalecki, el cual no es más que un redescubrimiento tardío de la teoría social de von Stein. La teoría del excedente de la economía política se erige, pues, en límite del principio de la demanda efectiva. 


\section{CONCLUSIONES}

Con base en su interpretación particular de la metáfora de la mano invisible enunciada por Smith en la Teoría de los sentimientos morales y del homo oeconomicus de Mill, descrito en Ensayos sobre algunas cuestiones disputadas en la economía politica, el marginalismo pretende resolver el conflicto social con el subterfugio de que el egoísmo lleva al bien común. En cambio, la economía imbuida por el principio de la demanda efectiva concibe el Estado como un titán encadenado por los olímpicos del liberalismo económico.

Desatado el titán, la sobreacumulación del capital y el desempleo serán remediados por la combinación de políticas fiscales y monetarias contracíclicas. Es paradójico que ambos enfoques concuerden en situar la problemática en la esfera de la circulación y eludan todo esfuerzo para averiguar el origen del poder de compra que hace factible el intercambio. La economía política llega más lejos al identificar en la esfera de producción el secreto que se esconde detrás de la tensa relación entre la sociedad civil y el Estado moderno.

El excedente que surge del intercambio desigual entre el trabajo y el capital es el pilar que sustenta el orden capitalista. La forma en que las relaciones sociales de producción condicionan la sociedad política se manifiesta en que esta depende del trabajo productivo. Aunque la dependencia es recíproca.

El orden social basado en la propiedad del capital requiere el Estado, un poder superior, para asegurar su reproducción. Las implicaciones que ello tiene en la política económica ayudan a entender el contexto actual de gobiernos que han hecho de la austeridad su razón de ser. Las crisis y las recesiones mundiales de las últimas cuatro décadas grabaron en piedra el epitafio de la política económica inspirada en la Teoría general de Keynes, en favor del ajuste estructural que ha convertido a los hacedores de políticas públicas en paladines de la austeridad.

El deterioro progresivo de la rentabilidad tuvo como respuesta la diligencia para delinear políticas fiscales y monetarias orientadas a elevar la participación del capital en el ingreso nacional. Su eficacia es constatada por las estadísticas que muestran la tendencia descendente de los salarios y la gradual concentración del acervo de riqueza (Shaikh, 2016; Piketty, 2017; Milanovic, 2018).

La tendencia a una desigual distribución funcional del ingreso es consustancial a la teoría de los salarios de Ricardo y de Marx: el salario relativo tiende a caer por obra de la fuerza que impulsa al capital a 
acumular para incrementar sus ganancias. Es justo entonces señalar que aunque las metas de inflación, la deflación salarial y la contención del gasto público toman la apariencia de instrumentos inspirados en axiomas marginalistas para combatir las recurrentes crisis del capitalismo, su misión está enraizada en el principal descubrimiento de la economía política; elevar el excedente durante las fases de crisis y recesión.

Así lo constatan trabajos recientes. Perrotini y Vázquez (2017) encuentran evidencia econométrica que respalda la hipótesis de que el ancla auténtica de la inflación son los costos laborales unitarios reales. Es decir, el verdadero propósito de los bancos centrales es aumentar la brecha entre la productividad y los salarios reales.

Se conectan así la política monetaria con la política fiscal y la deflación salarial dirigidas a mejorar la competitividad de los sectores exportadores, que oculta el imperativo de acrecentar el excedente. A este respecto, diversos trabajos respaldan la teoría de la ventaja absoluta del costo, de Anwar Shaikh (2016), los cuales demuestran estadísticamente que los términos reales de intercambio están supeditados a las condiciones técnicas de producción y a los salarios reales de los sectores exportadores (Martínez, 2017; Tsaliki et al., 2018).

En el concierto de la economía mundial, las empresas de los países con saldos comerciales positivos pueden producir mercancías a un costo menor que el de sus competidoras. Durante las crisis y las recesiones, la importancia de los mercados extranjeros para realizar el excedente condiciona la política fiscal e influye en las leyes que regulan el trabajo.

La flexibilización del mercado de trabajo y la menor carga tributaria que soportan las empresas reducen sus costos unitarios de producción, incrementan su excedente, desplazan a sus competidores $y$, finalmente, realizan las ganancias en los mercados internacionales. Visto así, el margen de acción que concede la economía política es menor que el que admite el principio de la demanda efectiva. Sin embargo, puesto que el objeto de la economía política es el bienestar físico de la sociedad, el reto al que debe dar respuesta es ofrecer las bases para una política económica alternativa que sea viable dentro de los límites que impone la teoría del excedente.

\section{REFERENCIA BIBLIOGRÁFICAS}

Bhaduri, A. y Marglin, S. (1990). Unemployment and the real wage: The economic basis for contesting political ideologies. Cambridge Journal of Economics, 14(4), 375-393. 
Blaug, M. (2001) [1962]. Teoría económica en retrospección. México DF: Fondo de Cultura Económica.

Boundi C., F. (2018). Valor y dinero en Marx. Revista de Economía Institucional, 20(38), 97-127.

Brunhoff de, S. D. (1967). La monnaie chez Marx. París: Problèmes.

Carchedi, G. (1991). Frontiers of political economy. Londres: Verso.

Carchedi, G. (2012). Could Keynes end the slump? Introducing the Marxist multiplier. International Socialism, 136. [http://isj.org.uk/ could-keynes-end-the-slump-introducing-the-marxist-multiplier/]

Cárdenas del Rey, L. (2018). Notas sobre la teoría kaleckiana de la inversión. Cuadernos de Economía, 41(115), 119-129.

Davidson, P. (2011). Post Keynesian macroeconomic theory. Cheltenham: Edward Elgar Publishing.

Guerrero, D. (1994). Historia del pensamiento económico heterodoxo. Madrid: Trotta.

Guerrero, D. (2010). Sismondi, precursor de Marx. Madrid: Maia.

Hegel, G. W. (2011) [1812-1813]. Ciencia de la lógica. Madrid: Abada.

Hegel, G. W. (1993) [1821]. Principios de la filosofía del derecho. Barcelona: EDHASA.

Jiménez-Barrera, Y. (2018). Aproximación crítica a las principales teorías sobre el cambio tecnológico. Problemas del desarrollo, 49(193), 171-192.

Kalecki, M. (1943). Political aspects of full employment. Political Quarterly, 14(4), 322-330.

Kalecki, M. (1956) [1954]. Teoría de la dinámica económica. Ensayo sobre los movimientos cíclicos y a largo plazo de la economía capitalista. México DF: Fondo de Cultura Económica.

Keynes, J. M. (1971) [1930]. A treatise on money: The pure theory of money, vol. 1. Londres: Macmillan.

King, J. E. (2005) [2002]. Una historia de la economía poskeynesiana desde 1936. Madrid: Akal.

Knapp, G. F. (1924) [1905]. The State theory of money. Londres: Macmillan.

Lavoie, M. (2014). Post-Keynesian economics: New foundations. Cheltenham: Edward Elgar Publishing.

Lerner, A. P. (1951). Economics of employment. Nueva York: McGraw-Hill.

Marcuse, H. (1994) [1941]. Razón y revolución. Hegel y el surgimiento de la teoría social. Barcelona: Altaya.

Martínez-H., F. A. (2017). The political economy of real exchange rate behavior: Theory and empirical evidence for developed and developing countries, 1960-2010. Review of Political Economy, 29(4), 566-596.

Marx, K. (1968) [1849]. Trabajo asalariado y capital. Barcelona: Alberto Aguilera.

Marx, K. (1974) [1843]. Crítica de la filosofía del Estado de Hegel. Barcelona: Grijalbo.

Marx, K. (1980a) [1956]. Teorías sobre la plusvalia I. México DF: Fondo de Cultura Económica (FCE).

Marx, K. (1980b) [1959]. Teorias sobre la plusvalía II. México DF: FCE.

Marx, K. (2002) [1859]. Contribución a la crítica de la economía politica. México DF: Siglo XXI. 
Marx, K. (2006a) El capital. Crítica de la economía politica, libro I [1867]. México DF: FCE.

Marx, K. (2006c) El capital. Crítica de la economía política, libro III [1894]. México: FCE.

Marx, K. (2014a) Elementos fundamentales para la crítica de la economía politica (Gründrisse) 1857-1858, cuaderno I [1939]. Madrid: Siglo XXI.

Marx, K. (2014b) Elementos fundamentales para la crítica de la economía politica (Gründrisse) 1857-1858, cuaderno I. [1939]. Madrid: Siglo XXI.

Milanovic, B. (2018). Desigualdad mundial: un nuevo enfoque para la era de la globalización [2016]. México: FCE.

Mill, J. S. (1997). Ensayos sobre algunas cuestiones disputadas en economía politica [1844]. Madrid: Alianza.

Minsky, H. (1986). Stabilizing an unstable economy: The lessons for industry, finance and government. Nueva York: McGraw-Hill.

Perrotini H., I., y Vázquez M., J. A. (2017). Is the wage rate the real anchor of the inflation targeting monetary policy framework?. Investigación económica, 76(302), 9-54.

Piketty, T. (2017). El capital en el siglo XXI. [1994]. México DF: Fondo de Cultura Económica.

Quesnay, F. (1972). Tableau économique [1758]. Londres: Macmillan.

Ricardo, D. (2004) On the principles of political economy and taxation [1821]. Works and correspondence of David Ricardo, vol. 1. Londres: Liberty Fund.

Rodríguez H., A. (2015). La riqueza. Historia de una idea. Madrid: Maia.

Roll, E. (2017) [1939]. Historia de las doctrinas económicas. México: FCE.

Rousseau, J. J (2011). Discurso sobre la economía politica [1754]. Madrid: Maia.

Rousseau, J. J (2014b). Du contrat social [1762]. París: Flammarion.

Rousseau, J. J. (2014a). Discours sur l'origine et les fondements de l'inégalité parmi les hommes [1755]. París: Flammarion.

Schumpeter, J. A. (2008). Capitalism, socialism and democracy [1942]. Nueva York: Harper.

Shaikh, A. (2016). Capitalism. Competition, conflict and crises. Nueva York: Oxford University Press.

Sismondi, J. C. L. S. (2016). Nuevos principios de economía politica o de la riqueza en sus relaciones con la población [1827]. Madrid: Icaria.

Smith, A. (2010). The theory of moral sentiments [1759]. Londres: Penguin.

Smith, A. (2012). An inquiry into the nature and causes of the wealth of nations [1776], vol. 1 y 2. Londres: Liberty Fund.

Théret, B. y Wieviorka, M. (1980). Crítica de la teoría del capitalismo monopolista de Estado [1978]. México DF: Terra Nova.

Tooke, T. (1857). A bistory of prices, and of the state of the circulation, from 1793 to 1837. Londres: Longman, Orme, Brown, Green, and Longmans.

Tsaliki, P., Paraskevopoulou, C. y Tsoulfidis, L. (2017). Unequal exchange and absolute cost advantage: Evidence from the trade between Greece and Germany. Cambridge Journal of Economics, 42(4), 1043-1086. 
Von Stein, L. (1981). Movimientos sociales y monarquía [1850]. Madrid:

Centro de Estudios Constitucionales.

Weber, M. (1998). El politico y el cientifico [1917]. Madrid: Alianza. 